\title{
MORBIDITY PATTERNS IN UNDERFIVE CHILDREN IN AN URBAN LOW SOCIOECONOMIC COMMUNITY OF GUNTUR CITY IN ANDHRA PRADESH
}

\author{
Prasada Rao Udaragudi ${ }^{1}$ (10) and Samson Sanjeeva Rao Nallapu ${ }^{2}$ (i) \\ ${ }^{1}$ Assistant Professor, Department of Community Medicine, NRI Medical College, Chinakakani, Mangalagiri Mandal, Guntur \\ District, Andhra Pradesh, India \\ ${ }^{2}$ Professor, Department of Community Medicine, NRI Medical College, Chinakakani, Mangalagiri Mandal, Guntur District, \\ Andhra Pradesh, India. Tel.: 9000443884
}

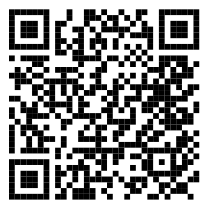

Received 6 June 2021

Accepted 18 June 2021

Published 30 June 2021

Corresponding Author

Samson Sanjeeva Rao Nallapu, sa

mson.nallapu@yahoo.com

DOI $10.29121 /$

granthaalayah.v9.i6.2021.4025

Funding: This research received no specific grant from any funding agency in the public, commercial, or not-for-profit sectors.

Copyright: (C) 2021 The Author(s). This is an open access article distributed under the terms of the Creative Commons Attribution License, which permits unrestricted use, distribution, and reproduction in any medium, provided the original author and source are credited.

\section{ABSTRACT}

Background: Retrospective morbidity data helps in prioritizing health conditions according their burden on the child and the family and to plan effective interventions. This study is set to look at the morbidity patterns in underfives in a low socio-economic area of Guntur city.

Methodology: This descriptive study conducted in the service area of the Urban Health Center (UHC) at Israilpet in Guntur city involved 740 underfive children from 6 randomly selected Anganwadi areas. After taking informed consent, the mothers of the children were subjected to a predesigned pretested structured questionnaire on current illnesses, 2 weeks recall of illnesses and illnesses over the last one year. The data is presented in the form of tables and percentages. Significant findings are subjected to tests of significance at $5 \%$ Level of Significance.

Results: Point prevalence of morbidity was $16.1 \%$ among boys and $10.7 \%$ among girls ( $\mathrm{p}$ value 0.03 ). Children with morbidity over last two weeks are $12.4 \%$ (boys $10.9 \%$ \& girls $13.9 \%$ ). Over one year, $52.2 \%$ had some illness (Boys $47.2 \%$ and Girls 52.8\%). The two-year-olds had the maximum illness burden $(69.5 \%)$ and the infants had the least (31.1\%) ( $p$ value 0.00000001$)$. Chronic illnesses like asthma, skin conditions etc. were seen in $5 \%$ of the children $(5.2 \%$ male and $4.8 \%$ female). $63 \%$ of the children were seen in private facilities while $37 \%$ were seen in a Govt. health facility. $11.1 \%$ of the children were seen only by unqualified practitioners.

Discussion: Morbidity in underfives is mainly focused on Acute Respiratory Infections (ARI) and diarrhoea which are the common causes of mortality in this age group. Chronic conditions of childhood may persist into adulthood and can influence both health and academic outcomes. Private sector health facilities including unqualified practitioners are sought after more than Government health facilities. 
Conclusion: There is an essential need to empower primary caregivers of children especially the mother to recognize early signs of childhood illness and seek appropriate care while also facilitating structural and procedural changes in the public healthcare system.

Keywords: Underfives, Morbidity, Prevalence, ARI, Diarrhoea, Health Seeking Behaviour

\section{INTRODUCTION}

Morbidity is a complex, multidimensional measure which is affected by individual and cultural factors and varies from place to place. Though an important and useful indicator of health status, morbidity data is limited compared to mortality. Tyagi et al. (2016) If children are symptomatic for particular illnesses, they are considered to be in a state of morbidity and this burden in the community can be presented as prevalence or an incidence. This retrospective information helps to evaluate the effectiveness of an existing healthcare system. Assessment of morbidity in underfives helps in prioritizing health conditions according to their burden on the child and the family and plan effective and efficient interventions. Hernandez and Kim (2020)

Globally in 2016, $8 \%$ of deaths among children under age five were caused by diarrhea while other leading causes of underfive deaths were acute respiratory infections and malaria. "World Health Statistics, Monitoring Health For The Sdgs, Sustainable Development Goals, Geneva: World Health Organization" (2018) Not only healthcare availability and access, but other actions like proper sanitation, balanced nutrition and vaccinations can bring down childhood morbidity. Children exposed to poor environmental conditions, in addition to poverty, malnutrition, and meager healthcare, are prone to a variety of infectious diseases. Wadgave (2013)

The two biggest killers of children in India and other developing countries continue to be pneumonia and diarrhea. As per the National Family Health Survey (NFHS 4), the annual incidence of diarrhea was $9 \%$ and that of ARI was 2.7\%. Dhirar et al. (2018) Takele $\mathrm{K}$ et al in Ethiopia found that male children, infants, toddlers, families where the fathers and mother have low educational levels, daily wage mothers, non-breast-fed children etc. had a high probability of acquiring illnesses. Takele et al. (2019)

Morbidity in underfive children may be due to acute infections and also due to chronic illnesses. Morbidity does restrict the activity of children leading to losses in terms of time while also disrupting the normal activities of the parents and family. Indrayan A et al suggest that morbidity in children can be measured by the number of children affected, the number of episodes or spells of sickness, the duration of illness and the severity of illness. Indrayan and Satyanarayana (2000)

Some measures of morbidity are prevalence (both point and period prevalence) and incidence. Point prevalence is the presence of morbidity at the time of con- 
tact obtained by a cross-sectional survey. Period Prevalence is the number of children affected during a specific period such as one or two weeks in a defined population. Duration of morbidity depends on its severity, competence of treatment and the child's innate immunity. In acute illnesses, the duration of sickness may be reported as a mean or a median with its standard deviation. Incidence is the number of episodes or the number of persons having onset of illness in a specific period of time. It can also be presented as number of persons becoming ill in a specified person time (person years, person months, person weeks) like for example incidence rate per 100 person-years. When a child gets two or three attacks of a disease, as in diarrhea, asthma or pneumonia, it can be shown in terms of attacks than incidence. Indrayan and Satyanarayana (2000) ARI is responsible for about 30 to 50 percent health facility visits and for about 20 to 40 percent of hospital admissions. Park (2011)

Risk factors for ARI include poverty, malnutrition, low birth weight, insufficient breast feeding, poor weaning, overcrowding, poor housing, air pollution, seasonality, and lack of access to adequate health services. Goel et al. (2012), Mathew et al. (2011) Gastro enteric infections continue to be a challenge in child health care globally and rotavirus vaccine is currently an important preventive measure in reducing both morbidity and mortality due to diarrhoeal diseases in children. Mokomane et al. (2018)

According to the UNICEF, during the years 2013 to 2018 in India, care seeking for children with symptoms of ARI was 78\% (world 68\%), ORS given for diarrhoea was 51\% (world 44\%) and care seeking for fever 73\% (world 67\%). "The State Of The World's Children" (2019) Factors known to predict increased survival in underfives healthcare during an episode of acute illness are mother's age and educational level, family religion and socioeconomic status, seeking health care in time among others. Mohapatra et al. (2019)

This study is set to look at under five children's morbidity patterns in a low socioeconomic area of Guntur city by estimating point prevalence, 2 week period prevalence and annual occurrence of illnesses as recalled by the mothers.

\section{METHODOLOGY}

This descriptive study was conducted in the service area of the Urban Health center (UHC) at Israilpet in Guntur city involving 740 children below five years of age. The duration of the study was from May 2018 to April 2019. Clearance was taken from the Institutional Ethical Committee (IEC) of the NRI Medical College. 6 out of 12 randomly selected Anganwadi catchment areas under the UHC were selected by simple random sampling. A household survey was done and all the under five children available at the time of visit were included in the study. Age of the child was calculated based on the date of birth given in the records of the Anganwadi teacher. A pretested structured questionnaire was developed keeping the study objectives in mind and 
administered to the mothers of the underfive children after taking an informed consent. Data was entered in MS Office Excel and analyzed with Epi Info version 3.4.3. The data is presented in the form of tables and percentages. Significant findings are subjected to tests of significance to look for associations between variables at $5 \%$ Level of Significance.

\section{RESULTS}

740 children (367 boys and 373 girls) were included in this study. Ages 0 to 12 months were 193 (girls 89), 13 to 25 months were 154 (girls 83), 25 to 36 months were 163 (girls 83), 37 to 48 months were 115 (girls 56) and 49 to 60 months were 115 (girls 52). According to the modified Kuppuswamy SES scale $82.8 \%$ of the families are Grades 3 and 4 (Lower). Most of the mothers (96.6\%) are between 20 to 30 years of age. $71.1 \%$ of the mothers are educated below secondary school, $28.9 \%$ being intermediate and above. $17.8 \%$ are in a consanguineous marriage. Families with good housing facilities (improved housing type, good drinking and washing water sources, functional toilet and safe cooking fuel) are $75.98 \%$.

Current illnesses: Point prevalence of morbidity among the children was $16.1 \%$ among the boys and $10.7 \%$ among the girls (total 13.4\%). The difference between the genders is statistically significant (Chi square $4.57, \mathrm{p}$ value 0.03 ). The maximum illness is seen in the 4-year-olds $(18.3 \%)$ and the least morbidity was seen in the infants (9.3\%), the rest averaging 13.9\% (Chi square 3.89, p value 0.05). Boys seem to have more morbidity across all ages except 2-year-olds. There is no significant difference between the genders regarding common illnesses seen at a single point of contact (Table 1 ).

Table 1 Under five children's current illnesses according to gender

\begin{tabular}{|c|c|c|c|c|}
\hline S. No & Illness & $\begin{array}{c}\text { Boys }(n=367) \\
\text { (\% of total } \\
\text { boys) }\end{array}$ & $\begin{array}{c}\text { Girls }(n=373) \\
\text { (\% of total } \\
\text { girls) }\end{array}$ & $\begin{array}{l}\text { Total (\% of total } \\
\text { illnesses) }\end{array}$ \\
\hline 1 & Fever & $15(4.1)$ & $12(3.2)$ & 27 (27.3) \\
\hline 2 & $\begin{array}{l}\text { Skin (Boils, } \\
\text { burns, rash, } \\
\text { fungal) }\end{array}$ & $11(3.0)$ & $5(1.3)$ & $16(16.2)$ \\
\hline 3 & $\begin{array}{c}\text { Respiratory } \\
\text { (ARI, } \\
\text { Pharyngitis, URI) }\end{array}$ & $9(2.5)$ & $6(1.6)$ & $15(15.2)$ \\
\hline 4 & Injury & $6(1.6)$ & $8(2.1)$ & $14(14.1)$ \\
\hline 5 & Worms & $3(0.8)$ & $5(1.3)$ & $8(8.1)$ \\
\hline 6 & Diarrhea & $5(1.4)$ & $3(0.8)$ & $8(8.1)$ \\
\hline 7 & $\begin{array}{l}\text { Misc (eye, fits, } \\
\text { insect bite, tooth, } \\
\text { thrush) }\end{array}$ & $3(0.8)$ & $5(1.3)$ & $8(8.1)$ \\
\hline \multirow[t]{2}{*}{8} & Pain Abdomen & $2(0.5)$ & $1(0.3)$ & $3(3.0)$ \\
\hline & Total & 54 (14.7) & $45(12.1)$ & $99(100.0)$ \\
\hline
\end{tabular}


The overall prevalence of congenital defects in this group of underfives is $1.6 \%$ (same in both genders). The common congenital defects are club foot, deaf and dumb, polydactyly, cleft lip, strabismus and hypospadias. Other conditions seen are avitaminosis (5.3\%), Pallor (3.5\%), Poor mental status (1.55), delay in milestones $0.9 \%$ ) and poor hearing (1.1\%).

Using WHO standards, $4.1 \%$ of the boys and $1.9 \%$ of the girls are lesser than 3 standard deviations from the median and therefore can be considered significantly malnourished. $10.4 \%$ of the boys and $8.8 \%$ of the girls are having moderate malnutrition. Only 1 girl was more than +3 SDs and is obese. Overall, $86.9 \%$ of the children are normal according to their weight for age (Boys $84.7 \%$ and girls $89 \%$ ).

Last 2 weeks recall of morbidity: Children with morbidity over last two weeks are $12.4 \%$ (boys $10.9 \%$ \& girls $13.9 \%$ ). The least morbidity is seen in infants $(9.33 \%)$ and the maximum was seen in ages 4 and 5 (13.9\% each). Among infants, girls are affected more (14.6\% Girls, 4.8\% Boys) (Chi Square 5.2, p value 0.02). The pattern of illnesses is given in Table 2 . Mean duration of illness was 3.9 days (SD 1.55). 2.2\% had less than 2 days of illness, $8.4 \%$ had 3 to 5 days of illness, and $1.9 \%$ had 6 days or more of illness.

\begin{tabular}{|c|c|c|c|c|}
\hline S.No & Illnesses & $\begin{array}{c}\text { Boys }(n=367)(\% \text { of } \\
\text { total boys })\end{array}$ & $\begin{array}{c}\text { Girls }(n=373)(\% o f \\
\text { total girls })\end{array}$ & $\begin{array}{l}\text { Total (\% of total } \\
\text { illnesses) }\end{array}$ \\
\hline 1 & Fever & $10(2.7)$ & $15(4.0)$ & $25(27.2)$ \\
\hline 2 & Diarrhea & $8(2.2)$ & $9(2.4)$ & 17 (18.5) \\
\hline 3 & $\begin{array}{c}\text { Injury / } \\
\text { Burns }\end{array}$ & 7 (1.9) & $10(2.7)$ & $17(18.5)$ \\
\hline 4 & ARI & $9(2.5)$ & $6(1.6)$ & $15(16.3)$ \\
\hline 5 & Worms & $3(0.8)$ & $4(1.1)$ & $7(7.6)$ \\
\hline 6 & Skin rash & $1(0.3)$ & $4(1.1)$ & $5(5.4)$ \\
\hline 7 & Nose bleed & $0(0)$ & $2(0.5)$ & $2(2.2)$ \\
\hline 8 & $\begin{array}{l}\text { Convul- } \\
\text { sions }\end{array}$ & $1(0.3)$ & $0(0)$ & $1(1.1)$ \\
\hline 9 & Head lice & $0(0)$ & $1(0.3)$ & $1(1.1)$ \\
\hline 10 & $\begin{array}{c}\text { Ear } \\
\text { infection }\end{array}$ & $1(0.3)$ & $0(0)$ & $1(1.1)$ \\
\hline \multirow[t]{2}{*}{11} & Toothache & $0(0)$ & $1(0.3)$ & $1(1.1)$ \\
\hline & Total & 40 (10.9) & 52 (13.9) & $92(100.0)$ \\
\hline
\end{tabular}

I year recall of morbidity: Looking at illness over one year, out of the 740 children, 52.2\% had some illness (Boys 47.2\% and Girls 52.8\%). The two-year-old children had the maximum illness burden (69.5\%) and the infants had the least (31.1\%) (Chi Square 63.57, p value $<0.001$ ). The difference between the genders is not significant statistically. List of diseases is given in Table 3 . 
Table 3 Incidence of illnesses overa period of 1 year $($ child years $=740)$

\begin{tabular}{|lll|}
\hline Illnesses over 1 year & No. of episodes of illness & Annual Incidence per $\mathbf{1 0 0}$ child years \\
\hline ARI & 205 & 27.7 \\
\hline Diarrhoea & 195 & 26.4 \\
\hline Fever & 61 & 8.2 \\
\hline Worm infestation & 38 & 5.1 \\
\hline Seizures & 32 & 4.3 \\
\hline Injury & 32 & 4.3 \\
\hline Skin conditions & 24 & 3.2 \\
\hline Abdominal pain & 15 & 2 \\
\hline Ear related & 2 & 0.3 \\
\hline Eye related & 2 & 0.3 \\
\hline Nose related & 2 & 0.3 \\
\hline Dental & 1 & 0.1 \\
\hline Jaundice & 1 & 0.1 \\
\hline
\end{tabular}

The annual prevalence of ARI in this study is $27.7 \%$. Infants had the least episodes of ARI (9.3\%) while the 2-year-olds had the maximum $(30.5 \%)$ followed by the 3 year-olds (27.0\%). In the four- and five-year-olds it was $19.2 \%$. (Table 4 )

Table 4 Underfives according to age in months and at least 1 episode of ARI / Diarrhoea in the last one year

\begin{tabular}{|c|c|c|c|c|c|}
\hline $\begin{array}{l}\text { Age } \\
\text { in } \\
\text { month }\end{array}$ & $\begin{array}{l}\text { Total } \\
\text { No. of } \\
\text { chil- } \\
\text { dren }\end{array}$ & $\begin{array}{c}\text { Minimum } \\
1 \text { episode } \\
\text { of ARI (\%) }\end{array}$ & $\begin{array}{c}\text { Statistical } \\
\text { significance }\end{array}$ & $\begin{array}{c}\text { Minimum } 1 \\
\text { episode of } \\
\text { Diarrhoea } \\
\text { (\%) }\end{array}$ & $\begin{array}{l}\text { Statistical } \\
\text { significance }\end{array}$ \\
\hline $\begin{array}{c}0 \text { to } \\
12\end{array}$ & 193 & $18(9.3)$ & & $28(14.5)$ & \\
\hline $\begin{array}{c}13 \text { to } \\
24\end{array}$ & 154 & $47(30.5)$ & & 49 (31.8) & \\
\hline $\begin{array}{c}25 \text { to } \\
36\end{array}$ & 163 & $44(27.0)$ & $\begin{array}{l}\text { Chi square } 28.66,4 \\
\text { degrees of freedom, p } \\
\text { value } 0.000009^{* *}\end{array}$ & $46(28.2)$ & $\begin{array}{l}\text { Chi Square } 22.35,4 \\
\text { degrees of freedom, } \\
\text { p value } 0.0002^{* *}\end{array}$ \\
\hline $\begin{array}{c}37 \text { to } \\
48\end{array}$ & 115 & $21(18.3)$ & & $21(18.3)$ & \\
\hline $\begin{array}{l}49 \text { to } \\
60\end{array}$ & 115 & $23(20.0)$ & & 18 (15.7) & \\
\hline Total & 740 & 153 (20.7) & & 162 (21.9) & \\
\hline
\end{tabular}

** Very significant

In this study population of underfive children, $21.9 \%$ had at least one diarrhoeal episode over the year. Prevalence of diarrhoeal episodes is $26.4 \%$. (Table 5 ) Gender wise, $20.7 \%$ of the boys and $23.1 \%$ of the girls had diarrhoeal episodes. It is seen that $14.5 \%$ of the infants had diarrheal episodes. Number of episodes is more in the 2year-olds (31.8\%) (Chi Square 22.35, degrees of freedom 4, p value 0.0002 ). $17.8 \%$ had a single episode of diarrhoea, $2.6 \%$ had two episodes, $1.2 \%$ had 3 episodes and $0.3 \%$ had 4 episodes. There is no significant gender difference. 
Table 5 Annual Episodes of ARI / Diarrhoea according to gender

\begin{tabular}{lllll}
\hline No. of episodes & \multicolumn{1}{c}{ ARI } & \multicolumn{3}{c}{ Diarrhoea } \\
& Boys (\%) $(\mathbf{n = 3 6 7 )}$ & Girls (\%) (n=373) & Boys (\%) (n=367) & Girls (\%) (n=373) \\
\hline One & $47(12.8)$ & $58(15.5)$ & $62(16.9)$ & $70(18.8)$ \\
Two & $26(7.1)$ & $18(4.8)$ & $11(3.0)$ & $8(2.1)$ \\
Three or more & $3(0.8)$ & $1(0.3)$ & $3(0.8)$ & $8(2.1)$ \\
Total & $76(20.7)$ & $77(20.6)$ & $76(20.7)$ & $86(23.1)$
\end{tabular}

Illness episodes: $45 \%$ of the underfive children had an episode or two of illness in the last one year and $7.2 \%$ had three or more episodes. Difference seen between the genders is not statistically significant. 3 or more episodes of illness were seen more in 5-year-olds (25.5\%) followed by the 3-year-olds (17.1\%) when compared to the other age groups (mean 8.5\%). 330 children (44.6\%) were disease free throughout the year. Number of days lost to illness annually amongst the 740 children comes to 2039 (Average of 2.76 days per child). $25.1 \%$ of the children lost 3 to 5 days in the year, while $20.8 \%$ lost more than 6 days to illness. Comparing days lost to illness with mother's education, in the secondary school educated and below group, more than 1-week days lost due to illness is higher (83.1\%) than in the Inter / Diploma and above group (16.9\%) (Chi Square 6.87, 2 degrees freedom, $p$ value 0.03). There is no difference in SES or religion. It is seen that children with consanguineous parentage had a higher number of illness episodes in the year $(46.2 \%)$ when compared to non-consanguineous (17.5\%) (Chi Square 7.13, p value 0.007).

Chronic illness: 37 (5\%) of the children have chronic illnesses $(5.2 \%$ male and 4.8\% female) common conditions being Asthma (15), skin conditions (9), Respiratory Allergies (5), Mental Retardation (4), Epilepsy (1), Ear, nose and throat issues (2) and heart disease (1). Prevalence of chronic illness is not associated with SES, religion or mother's education. Seasonal illnesses were reported in 75 children (rainy season 6, summer season 24 and the rest in winter).

Health seeking: $63 \%$ of the 386 children who had illness in the year were seen in private facilities (including unqualified practitioners $21 \%$ ) while $37 \%$ were seen in Govt. health facility. $11.1 \%$ of the children were seen only by unqualified practitioners. The local UHC was visited by $27.5 \%$ of the children. Purely public sector sources (GGH and UHC) of healthcare use by higher SES children was $5.7 \%$ while that of Lower SES children was $40.8 \%$ (Chi square 10.56, p value 0.001 ). The rest were using multiple public and private health care sources including unqualified practitioners. Of the 193 infants in the study, Govt health center was preferred for 44\% while $52 \%$ were shown in private health centers and $3.1 \%$ were taken to unqualified practitioners. In contrast $12.8 \%$ of the remaining underfives (13 to 60 months) were taken to an RMP (Chi square 12.8, p value 0.0004 ). 


\section{DISCUSSION}

An effort is made in the current study to list the common causes of illnesses as reported by mothers of underfive children at various stages of recall. It must be however kept in mind that the reporting of morbidity is based on the perception of illness and recall by caregivers and can be influenced by social and cultural factors like mother's literacy and family socio economic status. Manesh et al. (2008)

When morbidity in underfives is under discussion, the main illnesses that are focused on are ARI and diarrhoea. Wadgave HV et al in Sholapur, found that $40.5 \%$ of the underfives in an urban slum suffered with episodes of ARI and $18.33 \%$ with diarrhoea. Wadgave (2013) In comparison, Vyas S et al found in a study done in a rural area near Dehradun that diarrheal illness was (47.9\%) followed by ARI (22.21\%). Vyas et al. (2014) Wadgave HV et al also found that $84.76 \%$ children suffered from one or more than one morbidity (fever, worm infestations, skin infection, and injuries) the overall health morbidities being significantly more in female. Wadgave (2013)

Vyas $\mathrm{S}$ et al also suggest that the prevalence of sickness episodes is more in the toddler age group. Vyas et al. (2014)Sharma D et al found that ARI was more in 1-4 year age group (45.6\%), followed by infant age group (40\%) with no significant gender difference. Kuppusamy et al. (2013) Kumar SG et al found that the prevalence of ARI was highest in 0-12 months age group (63.2\%) with a higher burden on boys (62.9\%) as compared with girls. Kumar et al. (2015) Indrayan A et al state from their study in Lucknow, that the annual incidence per 100 child-years was as follows; respiratory (167), diarrhea (79.9), skin diseases (30.6) and pneumonia (9.6). Indrayan and Satyanarayana (2000)

Chronic health conditions may not only cause adverse health and academic outcomes but also persist into adulthood. Epilepsy is a common neurological condition seen in children and it can not only lead to learning disabilities and emotional problems but also affect social interactions. Miller et al. (2016)

Venkatachalam J et al state that though $98.9 \%$ of the under-five children in their study in Pondicherry experienced health problems in the previous three months, only $26 \%$ of them were taken within 24 hours to a health facility and that too mostly to private health facilities (60\%). Venkatachalam et al. (2014) Mishra K et al in their study in an urban slum of Bhubaneswar found that $77.7 \%$ of the underfives had some illness in the preceding 6 months and recorded 213 episodes of different morbidities among 260 children. Mohapatra et al. (2019) The place of preference for seeking care was Government Hospital (30.59\%) followed by medical store, private clinics, Anganwadi centers and quacks (2.28\%). Mohapatra et al. (2019) Minz et al in their study in an urban slum of Lucknow, said that the respondents mainly preferred a qualified private practitioner (65.4\%), followed by an unqualified private practitioner $(26.9 \%)$ and a tertiary care health center (7.8\%). Minz et al. (2017)

Under the new focus on Universal Health Coverage (UHC), the WHO advises member states to ensure that all children, irrespective of financial status of the family, to be 
able to access necessary health services. Child health services must be a mix of community and facility-based care designed as novel and custom-made approaches to increase access, coverage, and quality. WHO, Children: Improving Survival And WellBeing, WHO Fact Sheets (2020)

Awasthi $\mathrm{S}$ et al in their study done in rural Lucknow found that a structured pneumonia awareness session in the community along with some infrastructural improvements lead to improved care seeking from government facilities for children. Awasthi et al. (2019)

\section{CONCLUSION}

Ways to lower morbidity rates in underfive children include early diagnosis and prompt and optimal treatment thereby lessening the duration and impact of a disease. Other ways to reduce morbidity is through education and access to preventive healthcare so that delay in seeking treatment for the illness can be avoided. The challenge is to increase the ability of caregivers of children to recognize when to seek care and to facilitate appropriate care behavior. Empowerment of the mother who is a primary caregiver is crucial for the recognition of early signs of childhood illness and for seeking judicious care.

\section{ACKNOWLEDGEMENT}

The authors wish to thank the Principal and Management of NRI Medical College, Staff of the UHC, Israilpet, Guntur and the Anganwadi staff working in Israilpet for their help and cooperation. We are grateful to all the mothers and children who took part in this study.

\section{ETHICAL CLEARANCE}

Institutional Ethical Committee (IEC) clearance taken.

\section{REFERENCES}

Awasthi, S., Kumar, D., Mishra, N., Agarwal, M., \& Pandey, C. M. (2019). Effectiveness of various communication strategies for improving childhood pneumonia case management: a community based behavioral open labeled trial in rural Lucknow, Uttar Pradesh, India. BMC Public Health, 19(1), 1721-1721. Retrieved from https://dx.doi.org/10.1186/ s12889-019-8050-0 10.1186/s12889-019-8050-0

Dhirar, N., Dudeja, S., Khandekar, J., \& Bachani, D. (2018). Childhood Morbidity And Mortality In India - Analysis Of National Family Health Survey., 4, 335-338.

Goel, K., Ahmad, S., Agarwal, G., Goel, P., \& Kumar, V. (2012). A Cross Sectional Study On Prevalence Of Acute Respiratory Infections (ARI) In Under-Five Children Of Meerut District. India. J Community Med Health Educ, 9, 1000176-1000176. 
Hernandez, J., \& Kim, P. Y. (2020). Epidemiology Morbidity And Mortality. [Updated $2020 \mathrm{Feb}$ 2]. In: Statpearls [Internet]. Treasure Island (FL). Retrieved from Https://Www.Ncbi .Nlm.Nih.Gov/Books/NBK547668/

Indrayan, A., \& Satyanarayana, L. (2000). Measures Of Mortality And Morbidity In Children. Indian Pediatrics, 37, 515-521.

Kumar, S., Majumdar, A., Kumar, V., Naik, B., Selvaraj, K., \& Balajee, K. (2015). Prevalence of acute respiratory infection among under-five children in urban and rural areas of puducherry, India. Journal of Natural Science, Biology and Medicine, 6(1), 3-3. Retrieved from https://dx.doi.org/10.4103/0976-9668.149069 10.4103/0976-9668.149069

Kuppusamy, K., Bhoorasamy, A., \& Sharma, D. (2013). Prevalence of acute respiratory infections (ari) and their determinants in under five children in urban and rural areas of Kancheepuram district, South India. Annals of Tropical Medicine and Public Health, 6(5), 513-513. Retrieved from https://dx.doi.org/10.4103/1755-6783.133700 10.4103/ 1755-6783.133700

Manesh, A. O., Sheldon, T. A., Pickett, K. E., \& Carr-Hill, R. (2008). Accuracy of child morbidity data in demographic and health surveys. International Journal of Epidemiology, 37(1), 194-200. Retrieved from https://dx.doi.org/10.1093/ije/dym202 10.1093/ ije/dym202

Mathew, J. L., Patwari, A. K., Gupta, P., Shah, D., Gera, T., Gogia, S., Mohan, P., Panda, R., \& Menon, S. (2011). Acute respiratory infection and pneumonia in India: A systematic review of literature for advocacy and action: UNICEF-PHFI series on newborn and child health, India. Indian Pediatrics, 48(3), 191-218. Retrieved from https://dx.doi.org/ 10.1007/s13312-011-0051-8 10.1007/s13312-011-0051-8

Miller, G. F., Coffield, E., Leroy, Z., \& Wallin, R. (2016). Prevalence and Costs of Five Chronic Conditions in Children. The Journal of School Nursing, 32(5), 357-364. Retrieved from https://dx.doi.org/10.1177/1059840516641190 10.1177/1059840516641190

Minz, A., Agarwal, M., Singh, J. V., \& Singh, V. K. (2017). Care seeking for childhood pneumonia by rural and poor urban communities in Lucknow: A community-based crosssectional study. Journal of Family Medicine and Primary Care, 6(2), 211-211. Retrieved from https://dx.doi.org/10.4103/2249-4863.219987 10.4103/2249-4863.219987

Mohapatra, I., Mishra, K., \& Kumar, A. (2019). A study on the health seeking behavior among caregivers of under-five children in an urban slum of Bhubaneswar, Odisha. Journal of Family Medicine and Primary Care, 8(2), 498-498. Retrieved from https://dx.doi.org/ 10.4103/jfmpc.jfmpc_437_18 10.4103/jfmpc.jfmpc_437_18

Mokomane, M., Kasvosve, I., de Melo, E., Pernica, J. M., \& Goldfarb, D. M. (2018). The global problem of childhood diarrhoeal diseases: emerging strategies in prevention and management. Therapeutic Advances in Infectious Disease, 5(1), 29-43. Retrieved from https://dx.doi.org/10.1177/2049936117744429 10.1177/2049936117744429

Park, K. (2011). Epidemiology Of Communicable Diseases. Park'S Textbook Of Preventive And Social Medicine. 21sted. Jabalpur., 156.

The State Of The World's Children. (2019). Children, Food And Nutrition: Growing Well In A Changing World. UNICEF.

Takele, K., Zewotir, T., \& Ndanguza, D. (2019). Risk factors of morbidity among children under age five in Ethiopia. BMC Public Health, 19(1), 942-942. Retrieved from https://dx.doi .org/10.1186/s12889-019-7273-4 10.1186/s12889-019-7273-4

Tyagi, B. B., Mohanti, B. K., Hazarika, N., \& V, R. (2016). An Epidemiological Study On Morbidity Patterns Amongst Hospitalized Children In A New Tertiary Care Hospital Of Gurgaon. India International Journal of Medical And Health Research, 2(11), 6-14. 
Venkatachalam, J., Singh, Z., Purty, A. J., Narayanan, S., \& Sathya, G. R. (2014). A Study of Morbidity Pattern of Under Fives and Health Seeking Behavior of their Parents in a Coastal Region of Pondicherry, South India. Indian Journal of Public Health Research \& Development, 5(4), 41-41. Retrieved from https://dx.doi.org/10.5958/0976-5506 .2014.00009.6 10.5958/0976-5506.2014.00009.6

Vyas, S., Kandpal, S., Semwal, J., \& Deepshikha. (2014). A Study On Morbidity Profile And Associated Risk Factors In A Rural Area Of Dehradun. J Clin Diagn Res, 8(8).

Wadgave, H. (2013). Burden of health morbidities in under-fives in urban slum areas. Journal of Dr. NTR University of Health Sciences, 2(2), 96-96. Retrieved from https://dx.doi.org/ 10.4103/2277-8632.112333 10.4103/2277-8632.112333

WHO, Children: Improving Survival And Well-Being, WHO Fact Sheets. (2020, Sept). Retrieved from Https://Www.Who.Int/En/News-Room/Fact-Sheets/Detail/Children-Reducing -Mortality

World Health Statistics, Monitoring Health For The Sdgs, Sustainable Development Goals, Geneva: World Health Organization. (2018). 